\title{
Natural variation in tolerance to sub-zero temperatures among populations of Arabidopsis lyrata ssp. petraea
}

\author{
Matthew P. Davey ${ }^{1,2^{*}}$ (D), Ben G. Palmer ${ }^{2}$, Emily Armitage ${ }^{2}$, Philippine Vergeer ${ }^{3}$, William E. Kunin ${ }^{4}$,
}

F. Ian Woodward ${ }^{2}$ and W. Paul Quick ${ }^{2}$

\begin{abstract}
Background: Temperature is one of the most important abiotic factors limiting plant growth and productivity. Many plants exhibit cold acclimation to prepare for the likelihood of freezing as temperatures decrease towards $0^{\circ}$ C. The physiological mechanisms associated with enabling increased tolerance to sub-zero temperatures vary between species and genotypes. Geographically and climatically diverse populations of Arabidopsis lyrata ssp. petraea were examined for their ability to survive, maintain functional photosynthetic parameters and cellular electrolyte leakage integrity after being exposed to sub-zero temperatures. The duration of cold acclimation prior to sub-zero temperatures was also manipulated ( 2 and 14 days).

Results: We found that there was significant natural variation in tolerances to sub-zero temperatures among populations of A. petraea. The origin of the population affected the acclimation response and survival after exposure to sub-zero temperatures. Cold acclimation of plants prior to sub-zero temperatures affected the maximum quantum efficiency of photosystem II (PSII) $\left(F_{v} / F_{m}\right)$ in that plants that were cold acclimated for longer periods had higher values of $F_{v} / F_{m}$ as a result of sub-zero temperatures. The inner immature leaves were better able to recover $F_{v} / F_{m}$ from sub-zero temperatures than mature outer leaves. The Irish population (Leitrim) acclimated faster, in terms of survival and electrolyte leakage than the Norwegian population (Helin).

Conclusion: The ability to survive, recover photosynthetic processes and cellular electrolyte leakage after exposure to sub-zero temperatures is highly dependent on the duration of cold acclimation.
\end{abstract}

Keywords: Acclimation, Arabidopsis lyrata ssp. petraea, Chlorophyll fluorescence, Marginal populations, Survival

\section{Background}

Variation in freezing tolerance and the effectiveness of cold acclimation of plants before exposure to sub-zero temperatures varies within and between species. Furthermore, this variation is pronounced along latitudinal and altitudinal gradients, such that variation in response to low and sub-zero temperatures should be expected between species and genotypes which are geographically distant $[1,2]$. This response could also be affected by the length of time plants are cold acclimated prior to sub-zero temperatures in nature $[3,4]$. The ability of plants to

\footnotetext{
* Correspondence: mpd39@cam.ac.uk

${ }^{1}$ Current address: Department of Plant Sciences, Downing Street, Cambridge CB2 3EA, UK

${ }^{2}$ Animal and Plant Sciences, Western Bank, University of Sheffield, Sheffield, UK Full list of author information is available at the end of the article
}

acclimate to cold temperatures is related to a variety of metabolic and molecular processes $[5,6]$ such as those involved in maintaining or improving the integrity of the photosynthetic apparatus and cell membranes [7-9]. The photosynthetic apparatus can be severely affected by temperature $[10,11]$. For example, the rate at which electrons can be transported along the electron transport chain is decreased at low temperatures [12,13]. A decrease in photosystem II (PSII) activity can also occur at low temperatures $[14,15]$ and can be measured using chlorophyll fluorescence techniques that determine the maximum quantum efficiency of PSII $\left(F_{v} / F_{m}\right)$ [16-18]. The recovery of cold induced decreases in $F_{v} / F_{m}$ can vary according to genotypes within a plant species [19]. More recently, changes in chlorophyll fluorescence have been used to

(C) The Author(s). 2018 Open Access This article is distributed under the terms of the Creative Commons Attribution 4.0 International License (http://creativecommons.org/licenses/by/4.0/), which permits unrestricted use, distribution, and 
accurately quantify freezing damage in two ecotypes of the model species Arabidopsis thaliana [20]. Ehlert and Hincha [20] also used chlorophyll fluorescence imaging, linked to electrolyte leakage, to observe the spatial changes in $F_{v} / F_{m}$ of cold acclimated and non-acclimated, excised leaves of $A$. thaliana. There is an advantage of imaging $F_{v} / F_{m}$ in that the spatial changes in response to a potentially lethal treatment can be observed [21].

Alongside values of $F_{v} / F_{m}$, studies on the natural variation in freezing tolerance for A. thaliana have demonstrated a correlation between survivorship values (lethal temperature at $50 \%$ survival, $\mathrm{LT}_{50}$ ) and habitat minimum temperature [22], of which the genetic and molecular basis of this variation has been well characterised [23, 24]. However, unlike the annual species $A$. thaliana, cold acclimation and tolerance to sub-zero temperatures is especially critical to survival in perennial Arctic-Alpine plants as they are exposed to a wider range of temperatures over the year. Phenotypic, genetic and metabolic differences have been reported between geographically isolated populations of the Arctic-Alpine perennial Arabidopsis lyrata. ssp. petraea (hereafter A. petraea) [25-29]. Therefore, we hypothesised that there would be inherent differences in other phenotypic characteristics that are associated with changes in cold acclimation duration and exposure to sub-zero temperatures, namely the maximum efficiency of photosystem II $\left(F_{v} / F_{m}\right)$ and the integrity of cellular membranes (electrolyte leakage) among the populations of this species. To this end, geographically and climatically diverse populations of $A$. petraea were examined for their ability to survive, maintain functional photosynthetic parameters and avoid cellular electrolyte leakage after being exposed to sub-zero temperatures following a period of cold temperature (acclimation). Plants from the Norwegian high altitude population (Helin) and the Irish low altitude population (Leitrim) were selected for further study due to the large differences experienced by these two populations in mean annual temperatures (Table 1); the number of days recorded at sub-zero temperatures and snow cover (Fig. 1) and the percent survival of plants at sub-zero temperatures (Fig. 2). It was also hypothesised that plants from the Norwegian population would exhibit greater tolerance to sub-zero temperatures than plants from the Irish population. The treatment temperature of $-9{ }^{\circ} \mathrm{C}$ was chosen for single sub-zero temperature exposures for \% survival, $F_{v} / F_{m}$ and electrolyte leakage measurements as this was the temperature at which there was the greatest difference between the percent survival of Leitrim and Helin plants (Fig. 2).

\section{Results}

\section{Climate data}

Across all the sites (Table 1), there was large variation in the number of days where the minimum temperature dropped below zero degrees Celsius and in the number of days with snow cover (Fig. 1). The Leitrim site (Ireland) had the fewest days at sub-zero temperatures and the least number of days with snow cover. The sites in Norway had the greatest number of days at sub-zero temperatures and with snow cover, followed by Sweden and then Icelandic sites.

\section{Short term ( 2 days) cold acclimation}

The percent survival of plants exposed to sub-zero temperatures was dependent on the plants' geographic origin (Fig. 2). There was a difference of $2.4^{\circ} \mathrm{C}$ between the lowest and highest lethal temperature for $50 \%$ death $\left(\mathrm{LT}_{50}\right)$ for the populations of A. petraea (Sweden, Notsand $-8.6^{\circ}$ $\mathrm{C}$ and Norway low altitude (Bovra) $-6.2^{\circ} \mathrm{C}$, respectively) (Table 1). The temperature at which there was the largest differential in survival was $-7{ }^{\circ} \mathrm{C}$ where $76 \%$ of the Swedish coastal (Notsand) population survived while only $34 \%$ of the Norwegian low altitude (Bovra) population survived. The largest difference between survival for the targeted populations occurred at $-9{ }^{\circ} \mathrm{C}$ where $46 \%$ of the Irish (Leitrim) population survived while only $27 \%$ of the Norwegian high altitude (Helin) population survived.

\section{Maximum efficiency of photosystem II $\left(F_{v} / F_{m}\right)$}

In Norwegian (Helin) and Irish (Leitrim) populations, there were spatial differences in the recovery of the maximum efficiency of photosystem II $\left(F_{v} / F_{m}\right)$ (Fig. 3). The

Table 1 Location and altitude for each population of Arabidopsis lyrata ssp. petraea in this study

\begin{tabular}{|c|c|c|c|c|c|c|c|}
\hline Country & Population & $\begin{array}{l}\text { Latitude } \\
\text { (decimal degrees) }\end{array}$ & $\begin{array}{l}\text { Longitude } \\
\text { (decimal degrees) }\end{array}$ & $\begin{array}{l}\text { Altitude } \\
\text { (masl) }\end{array}$ & $\begin{array}{l}\text { Average yearly site } \\
\text { temperature }\left({ }^{\circ} \mathrm{C}\right)\end{array}$ & Site description & $\mathrm{LT}_{50}\left({ }^{\circ} \mathrm{C}\right)$ \\
\hline Iceland & Raudholar & 64.093 & 21.749 & 90 & 5.0 & Coastal & -7.8 \\
\hline Iceland & Sandfell & 64.073 & 21.683 & 119 & 4.7 & Inland, low altitude & -7.7 \\
\hline Sweden & Notsand & 62.609 & 18.062 & 3 & 7.5 & Coastal, low altitude & -8.6 \\
\hline Norway & Bovra & 61.770 & 8.419 & 493 & 4.6 & Low altitude & -6.2 \\
\hline Norway & Spiterstulen & 61.658 & 8.427 & 953 & 3.6 & High altitude & -6.5 \\
\hline Norway & Helin & 61.046 & 8.666 & 1141 & 4.5 & High altitude & -7.4 \\
\hline Ireland & Leitrim & 54.383 & 8.377 & 355 & 8.8 & Inland, low altitude & -7.7 \\
\hline
\end{tabular}

Masl metres above sea level. Lethal temperature for $50 \%$ survival after exposure to sub-zero temperatures after two days cold acclimation at $2{ }^{\circ} \mathrm{C}\left(\mathrm{LT}_{50}\right)$ 


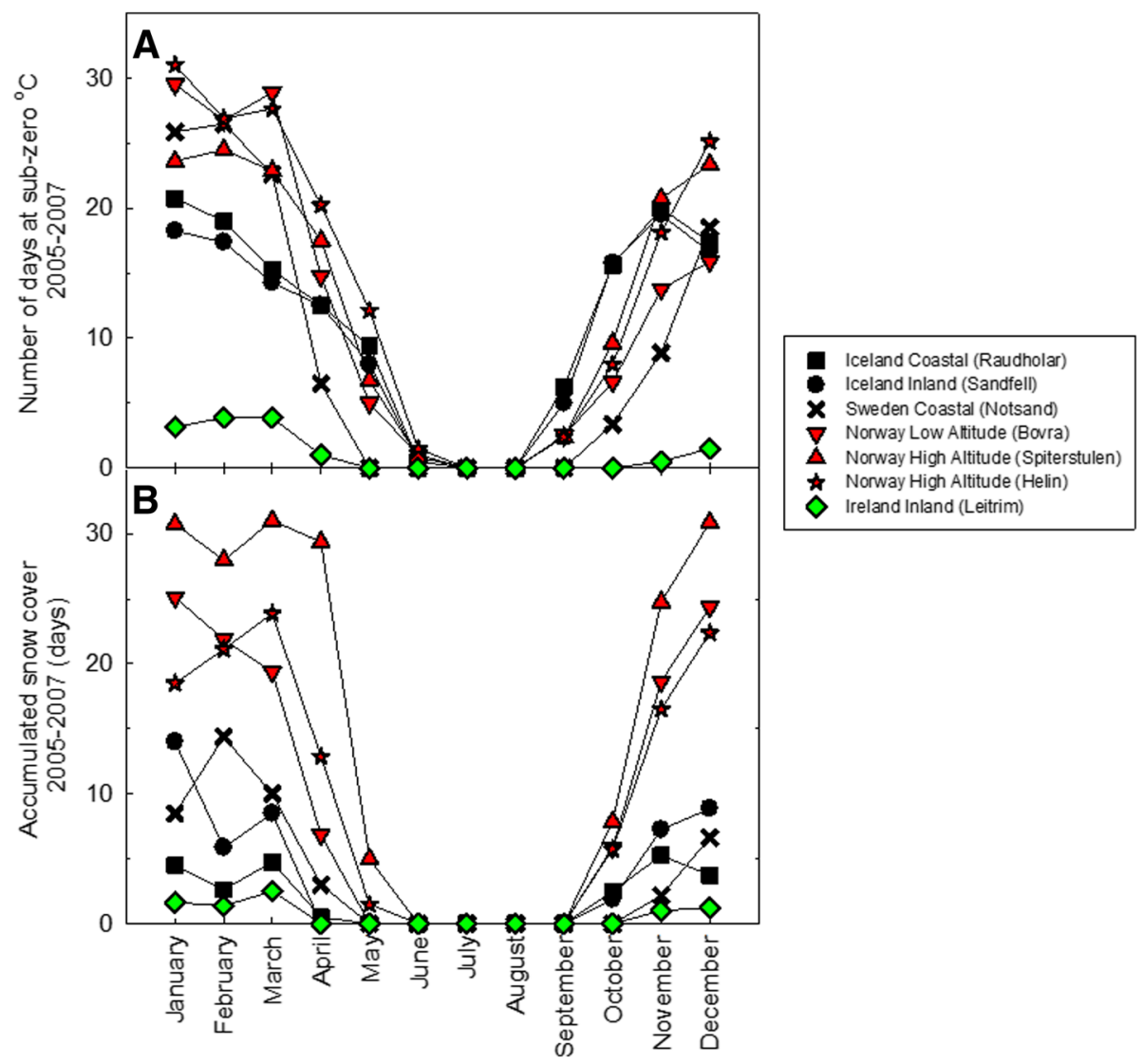

Fig. 1 a: The number of days where the minimum temperature dropped below zero degrees Celsius for each site. $\mathbf{b}$ : The number of days with snow cover defined as the number of days with a variation in daily $(24 \mathrm{~h})$ temperature of less than 2 degrees Celsius and with temperatures constantly below 1 degree Celsius. Temperature recordings were taken every 120 min over a period of two years (August 2005 - August 2007)

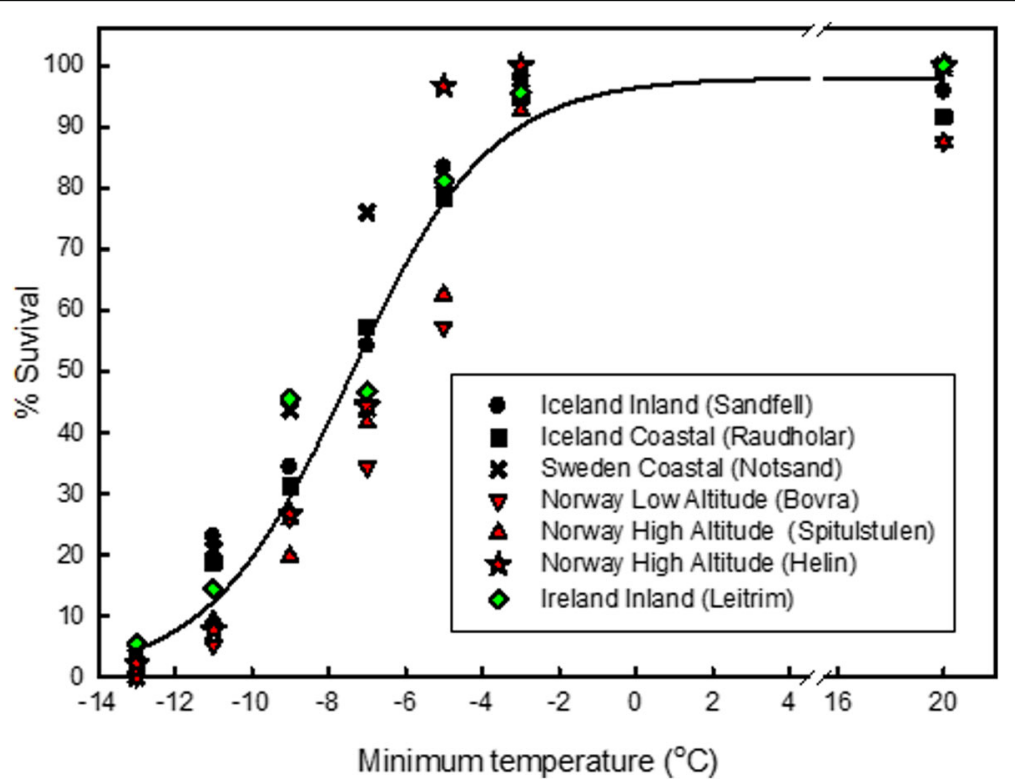

Fig. 2 Percent survival of Arabidopsis lyrata ssp. petraea from separate populations, 14 days after exposure to sub-zero temperatures. Plants were exposed to $2{ }^{\circ} \mathrm{C}$ for 2 days prior to exposure to sub-zero temperatures. $n=90$ to 96 apart from $20^{\circ} \mathrm{C}$ where $n=24$. Curve represents mean survival of all populations. $L T_{50}$ values are presented in Table 1 
ability of the inner leaves to recover $F_{v} / F_{m}$ and survive sub-zero temperatures is shown by $F_{v} / F_{m}$ images taken 2 , 5 and 16 days post sub-zero treatment of the same plant for each population (Fig. 3). The surviving inner leaves have grown whereas the older damaged leaves died after 16 days. There was a substantial between-population difference with the Irish population maintaining $F_{v} / F_{m}$ in more leaves (mature and immature) compared to the Norwegian population.

To qualify whether the inner whorl recovery was responsible for final plant survival after the sub-zero treatments, the average $F_{v} / F_{m}$ values of the immature inner whorl and mature outer whorl leaves of each plant was obtained by selecting such regions in each image. This confirmed that there was a difference in $F_{v} / F_{m}$ values between the inner immature leaves and the outer mature leaves (Fig. 4). The final percent survival of the two populations differed between the two populations, with plants from the Irish population able to survive lower temperatures (Fig. 4). The survival of the Irish plants was correlated to the $F_{v} / F_{m}$ values of the inner leaves $\left(F_{v} / F_{m}>0.5\right)$ as the sharp decrease in $F_{v} / F_{m}$ at $-13{ }^{\circ} \mathrm{C}$ was related to a severe decrease in the number of surviving plants. This pattern was not replicated in the outer mature leaves. Similarly in the Norwegian plants, the survival of the plants was related to maintaining $F_{v} / F_{m}$ values of the inner leaves as the $F_{v} / F_{m}$ of the outer leaves values were less than 0.2 from $-11.5^{\circ} \mathrm{C}$ onwards.

\section{Short and long term ( 2 and 14 days) cold acclimation}

An increase in cold acclimation duration, from 0 to 2 and then 14 days, resulted in an increase in the number of plants surviving $-9{ }^{\circ} \mathrm{C}$ temperatures (Table 2). After 2 days of cold acclimation, more Irish plants survived than Norwegian plants. However, after 14 days acclimation, both populations had a similar number of plants surviving the sub-zero temperatures. The increase in survivorship with increased acclimation duration was reflected in the changes in $F_{v} / F_{m}$ and electrolyte leakage results (Table 2; Fig. 5) where after 2 days cold acclimation, the $F_{v} / F_{m}$ was significantly greater in plants from Ireland (Leitrim), compared to those from Norway (Helin). There was no significant difference in $F_{v} / F_{m}$ between populations in plants exposed to 14 days cold acclimation prior to a $-9{ }^{\circ} \mathrm{C}$ treatment (Table 2).

Similarly, there were contrasting cellular electrolyte leakages of these two populations when exposed to sub-zero

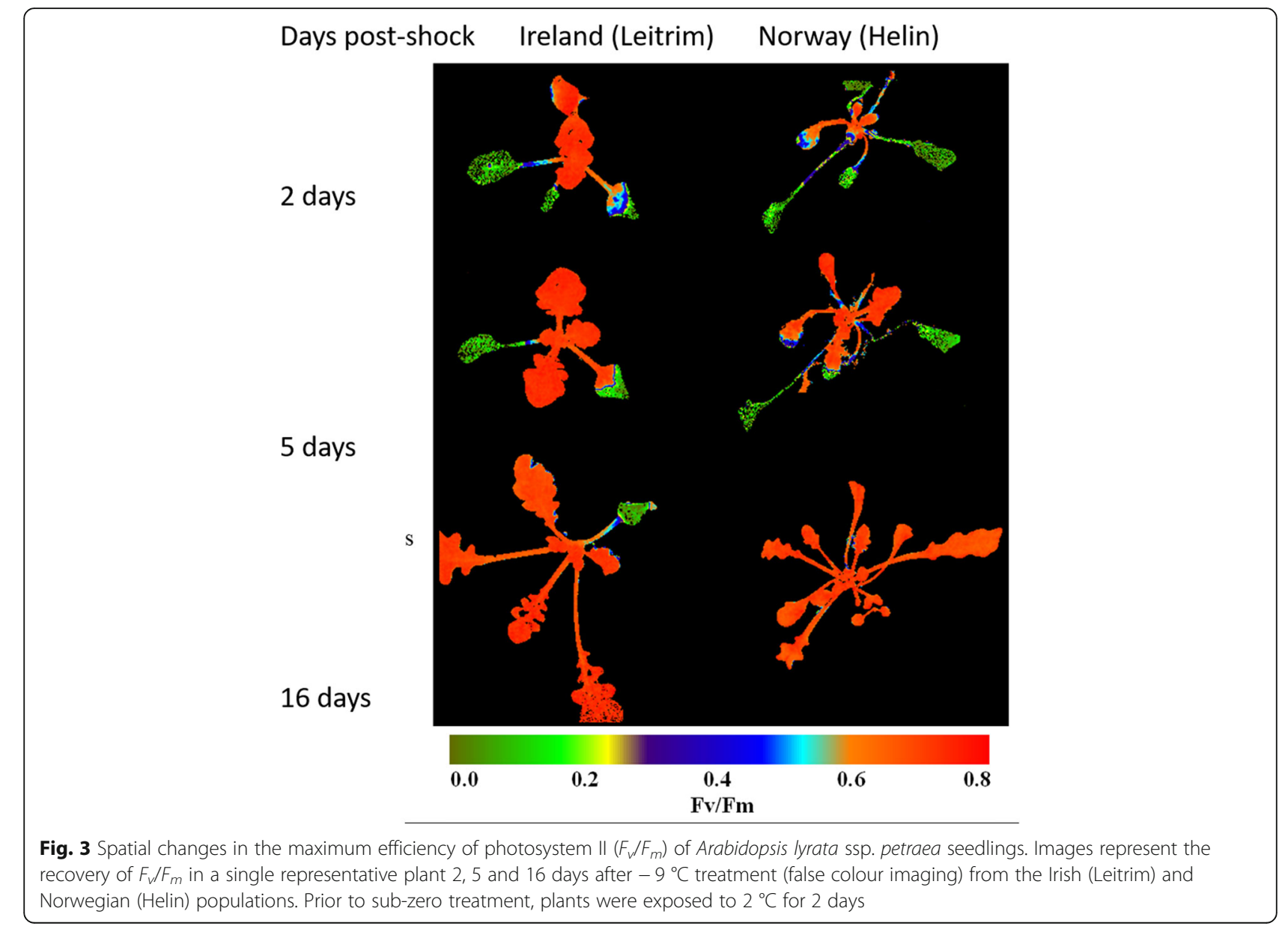




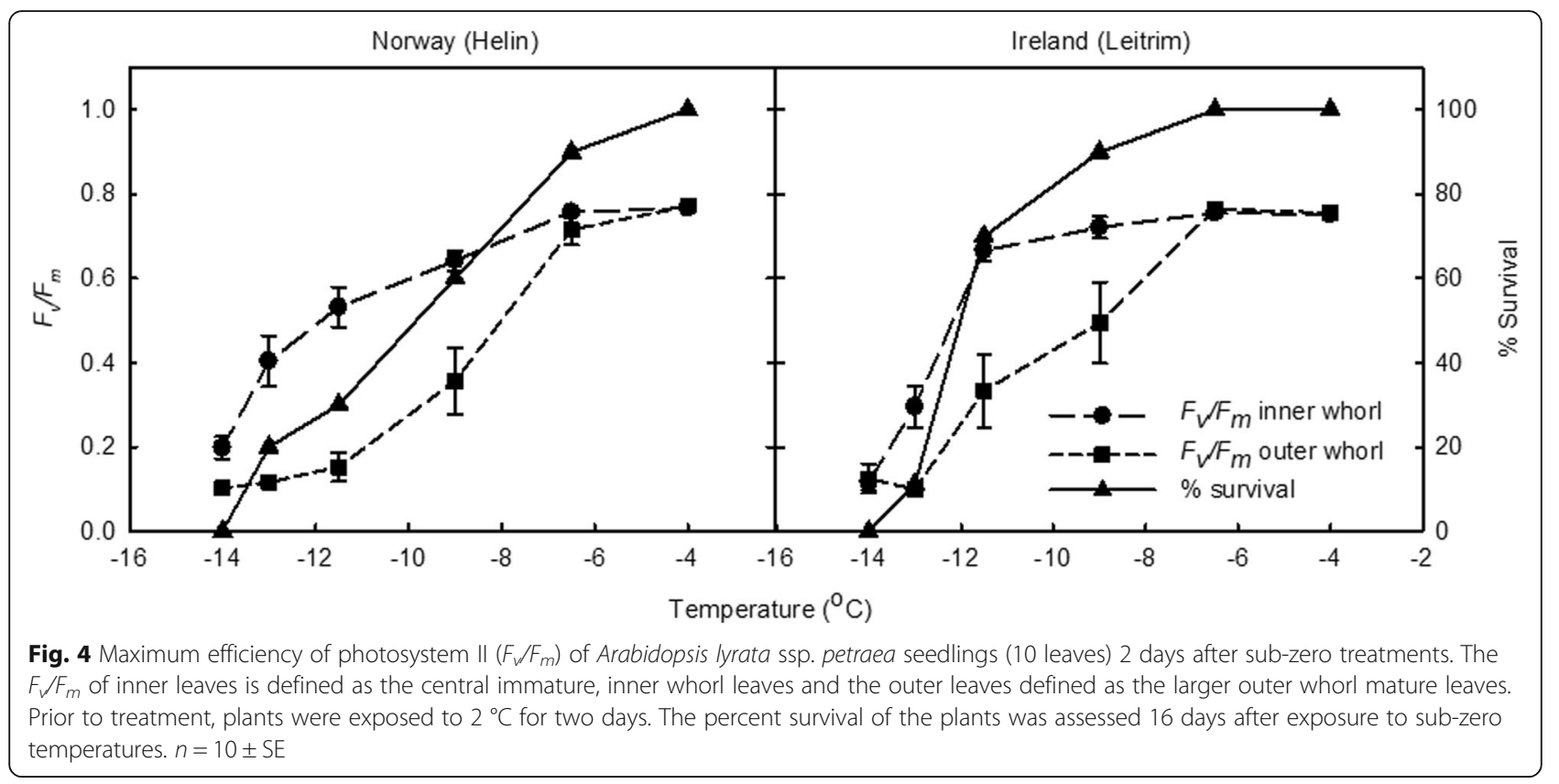

temperatures and different cold acclimation durations (Table 2). The cellular electrolyte leakage was significantly lower in the Irish plants exposed to $-9{ }^{\circ} \mathrm{C}$ after a 2 day cold acclimation period, compared to Norway plants. However, in plants exposed to 14 days cold acclimation, the electrolyte leakage was substantially lower in Norway plants compared to Ireland, but this difference was not statistically significant. Increased acclimation duration in the Irish population resulted in the temperature at which $50 \%$ electrolyte leakage occurs $\left(\mathrm{TEL}_{50}\right)$ decreasing from $-4.5{ }^{\circ} \mathrm{C}$ in the control samples with no prior cold acclimation to $7.6^{\circ} \mathrm{C}$ in 2 day acclimated samples to $-7.8^{\circ} \mathrm{C}$ in 14 day acclimated samples. This reduction in leakage was even more pronounced in the Norwegian population where the $\mathrm{TEL}_{50}$ of electrolyte leakage was reduced from $-4.2{ }^{\circ} \mathrm{C}$ in the no acclimation samples to $-6.7^{\circ} \mathrm{C}$ in 2 day acclimated samples to $-9.2{ }^{\circ} \mathrm{C}$ in 14 day acclimated samples.

\section{Discussion}

This study has shown that there is significant intraspecific variation in freezing tolerance, chlorophyll fluorescence and cellular electrolyte leakage in response to sub-zero temperatures. There were significant differences in the ability of plants from different geographic origins to survive sub-zero temperatures. Despite the fact that average annual temperatures for the Swedish

Table 2 Percent survival, maximum efficiency of photosystem $\|\left(F_{v} / F_{m}\right)$ and electrolyte leakage at $-9{ }^{\circ} \mathrm{C}$ and temperature for $50 \%$ electrolyte leakage (TEL ${ }_{50}$ ) of two individual populations of Arabidopsis lyrata ssp. petraea after exposure to sub-zero temperatures for one night

\begin{tabular}{|c|c|c|c|}
\hline & Cold acclimation duration (days) & Helin (Norway) & Leitrim (Ireland) \\
\hline \multirow[t]{3}{*}{$\%$ survival after exposure to $-9^{\circ} \mathrm{C}$} & 0 & 0 & 8 \\
\hline & 2 & 27 & 46 \\
\hline & 14 & 81 & 76 \\
\hline \multirow[t]{2}{*}{$F_{v} / F_{m}$ after exposure to $-9{ }^{\circ} \mathrm{C}$} & 2 & $0.35( \pm 0.06)$ & $0.57( \pm 0.04)^{* *}$ \\
\hline & 14 & $0.43( \pm 0.02)$ & $0.48( \pm 0.03) \mathrm{ns}$ \\
\hline \multirow[t]{3}{*}{ Electrolyte leakage (\%) at $-9{ }^{\circ} \mathrm{C}$} & 0 & $96.0( \pm 2.0)$ & $97.3( \pm 0.2) \mathrm{ns}$ \\
\hline & 2 & $99.3( \pm 1.0)$ & $89.2( \pm 2.6) *$ \\
\hline & 14 & $48.2( \pm 13.0)$ & $74.8( \pm 17.0) \mathrm{ns}$ \\
\hline \multirow[t]{3}{*}{$\mathrm{TEL}_{50}\left({ }^{\circ} \mathrm{C}\right)$} & 0 & -4.2 & -4.5 \\
\hline & 2 & -6.7 & -7.6 \\
\hline & 14 & -9.2 & -7.8 \\
\hline
\end{tabular}

Sub-zero temperatures were applied at a rate of $-2{ }^{\circ} \mathrm{C}$ per hour after 0,2 or 14 days cold acclimation at $2{ }^{\circ} \mathrm{C}$. Statistically significant differences between populations are indicated by ${ }^{*}=P \leq 0.05 ;{ }^{* *}=P \leq 0.01$; ns = not significant 


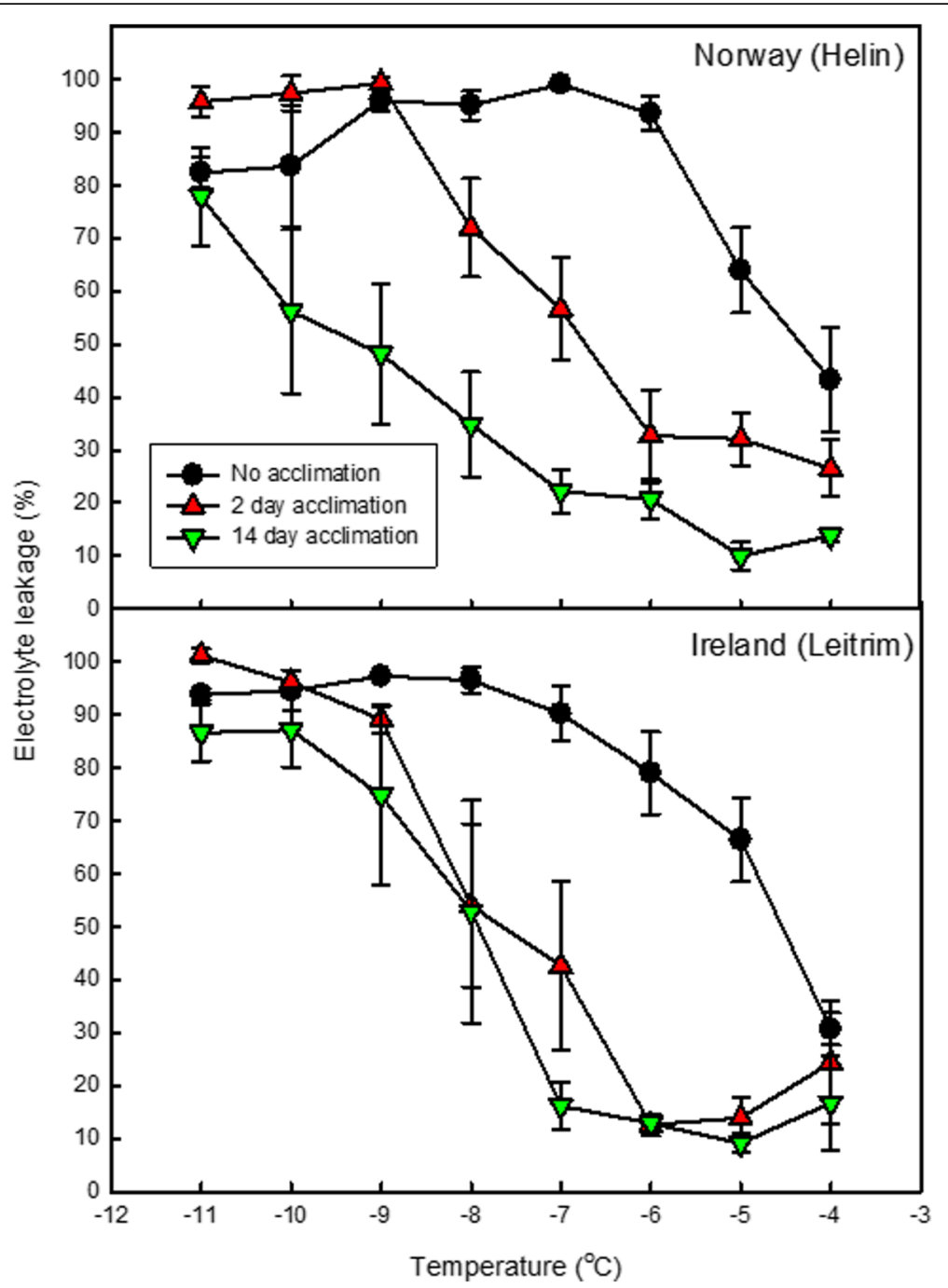

Fig. 5 Cellular electrolyte leakage (\%) of excised mature leaves from two individual populations of Arabidopsis lyrata ssp. petraea after exposure to a range of sub-zero temperatures. Sub-zero temperatures applied after no acclimation or 2 or 14 days acclimation at $2^{\circ} \mathrm{C} . n=4 \pm \mathrm{SE}$. TEL $n 0$ values are presented in Table 2

populations were higher than the Norwegian populations (Table 1), the Swedish population (Notsand) had the greater tolerance to sub-zero temperatures $\left(\mathrm{TEL}_{50}\right.$ at $8.6{ }^{\circ} \mathrm{C}$ ), whereas a Norwegian population (Bovra) had the lowest tolerance $\left(\mathrm{TEL}_{50}-6.2^{\circ} \mathrm{C}\right)$ (Fig. 1). One explanation could be that although plants from Norwegian and Swedish populations would experience a similar number of days below zero degrees $C$ when grown in the field, the number of days of snow cover measured in the Norwegian populations was greater than the Swedish sites (Fig. 1). This would allow the Swedish population to have a longer cold acclimation period, favouring plants with a higher tolerance to freezing. However, other factors may be the cause of the difference, such as coastal humidity or the absence of snow cover in a cold period may cause soils to freeze to greater depths and expose plants to greater physical and physiological stress [30]. This snow cover would thus provide greater insulation for the Norwegian plants whilst the Swedish plants would be exposed to colder, sub-zero, temperatures. The majority of plants did not survive temperatures below $10{ }^{\circ} \mathrm{C}$, however, those that did were mostly from populations with low snow cover sites (Iceland, Ireland and Sweden). Such variation in the number of plants able to survive such sub-zero temperatures will be critical in establishing and maintaining populations, especially in marginal populations where the inherent ability to survive sub-zero temperatures outside the population norm would be critical in expanding the population.

The detailed studies on the Leitrim (Irish) and Helin (Norwegian) populations revealed population-specific responses to cold acclimation duration and sub-zero temperatures. 
More plants from the Irish population were able to survive sub-zero temperatures than the Norwegian population, especially when acclimated for 2 days. That plants from warmer locations would be more tolerant to sub-zero temperatures than those originating from colder locations was counter to our expectations. One explanation could be that this is due to adaptive phenotypes obtained from a historical climate which are still conserved in the population [31]. However, this effect was somewhat reversed, albeit not significantly so, when plants were acclimated for 14 days. Therefore, cold acclimation and survival duration is critical for young seedlings prior to a freezing event, such as that experienced on a clear frosty night [32]. Alternatively, as plants in the Irish sites would not have experienced sub-zero conditions during the summer and most of the autumn months, they may have adapted to acclimate faster for an approaching winter. This is in contrast to the Norwegian plants where summer and autumn nightime temperatures regularly fall to below zero degree $C$ (Fig. 1) and do not clearly indicate the approach of winter.

Chlorophyll fluorescence measures the state of photosystem II (PSII) such that if it is damaged, $F_{v} / F_{m}$ may be reduced. This indicates that damage from sub-zero temperatures is lessened with an increase in cold acclimation and plants become more low temperature and sub-zero tolerant. It was evident from the $F_{v} / F_{m}$ imaging that the Irish population had a greater area of maintained PSII in the inner immature leaves and the outer mature leaves than the Norwegian population (Fig. 3), and that this was related to recovery and survival of the plants (Fig. 4). This is similar to results in Demmig-Adams [16], Haldimann et al. [33, 34] where leaves of cold acclimated herbaceous plants exhibit a substantially decreased susceptibility to photoinhibition, possibly caused by a greater capacity to dissipate energy and increase carotenoid concentrations such as zeaxanthin. That inner younger leaves are more likely to survive cold temperature shocks suggests that developmental processes are central to the acclimation process and likely to involve morphological and metabolic changes that are not possible in mature leaves [35]. Improved acclimation at 14 days rather than 2 days may therefore just reflect the number of leaves that were developing during the acclimation period. Another explanation is that the $F_{v} / F_{m}$ was an indirect measure for damage (and subsequent recovery) of the cell membranes (measured as electrolyte leakage).

The measurements of electrolyte leakage were in line with other reports on cold acclimation in Arabidopsis thaliana genotypes $[9,36]$. Observations of electrolyte leakage indicated two different strategies for cold acclimation, a fast and a slow acclimator, where plants from the Helin population were slower to alter their cell membrane properties than those from the Leitrim population (Fig. 5; Table 2). However, overall the plants from Helin had less cellular electrolyte leakage after 14 days of cold acclimation (48\% leakage; $\mathrm{TEL}_{50}$ of $9.2{ }^{\circ} \mathrm{C}$ ), than plants from the Leitrim population $(74.8 \%$; $\mathrm{TEL}_{50}$ of $\left.-7.8{ }^{\circ} \mathrm{C}\right)$. Although the electrolyte leakage measurements were not directly correlated with the final percent survival of the populations at various temperatures, these data show that the Helin population is able to withstand colder temperatures better than the Leitrim population, so long as the plants have had a long cold acclimation period.

\section{Conclusion}

These findings show that there is significant natural variation in tolerances to sub-zero temperatures among populations of $A$. petraea, which may signify plant adaptation to local climates. It was hypothesised that acclimation of plants prior to sub-zero temperatures would have an effect on chlorophyll fluorescence, and that the origin of the population would have an effect on acclimation response and survival after exposure to sub-zero temperatures. This was seen to be the case. However, as only $F_{v} / F_{m}$ values were measured, it is not clear whether this would be due to changes in the operating efficiency of PSII $\left(\Phi_{\mathrm{PSII}}\right)$ or as slowly recovering non-photochemical quenching [37]. The ability of $A$. petraea to survive, maintain functional photosynthetic parameters and cellular electrolyte leakage integrity after being exposed to sub-zero temperatures is likely to be inherently different between the populations. Large differences in phenotype have been reported for $A$. petraea across its Northwest European range [29], as well as genetic differences $[25,26,38]$ and metabolite differences between some populations [27, 28]. Our data build on these studies and strongly indicate that differences in cold acclimation, survival and photosynthetic activity recovery may also be inherent among populations of this species.

\section{Materials and methods Climate data}

To measure temperature in the field populations, four temperature monitoring probes (Thermocron iButtons Model DS1922L; Maxim Dallas Inc) were placed out in all populations, buried $1 \mathrm{~cm}$ below the soil surface to avoid direct radiation exposure. The location of two of these temperature monitoring probes was chosen subjectively to be the warmest and coldest microsites of the site (based largely on slope and aspect). The locations of the other two probes were chosen at random. The probes were always located within $10 \mathrm{~cm}$ of an A. petraea plant. Temperature recordings were taken every 120 min over a period of 2 years (August 2005 - August 2007), which allowed us to analyse regional microclimate variation in mean and extreme temperatures. The number of days with snow cover was defined as the number 
of days with a variation in daily ( $24 \mathrm{~h})$ temperature of less than $1{ }^{\circ} \mathrm{C}$ and with temperatures constantly below $1{ }^{\circ} \mathrm{C}$. The number of days where the minimum temperature dropped below $0{ }^{\circ} \mathrm{C}$ was also calculated.

\section{Seed collection and plant growth conditions}

Seeds of Arabidopsis lyrata ssp. petraea were sourced and collected from geographically separated populations within Ireland, Norway, Sweden and Iceland (Table 1). Seed collections were carried out with under permission from all land owners and complied with institutional, national, or international guidelines and legislation. All seeds were half-sibships from the maternal plants. Seeds of each population were sown in Levington M3 compost within individual plug trays. Populations were randomised within each tray and trays were randomly re-positioned every other day. Plants were watered from the base of the pot when required with reverse osmosis (RO) water. No additional nutrients were added to the soil or water. Plants were established in controlled-environment growth cabinets (Conviron Controlled Environments Limited, Canada) set to a $12 / 12 \mathrm{~h}$ day/night cycle; $20 / 15{ }^{\circ} \mathrm{C}$ day/ night; $60 \%$ humidity, atmospheric $\mathrm{CO}_{2}$ concentration $400 \mathrm{ppm} \mathrm{CO}_{2}$ and photosynthetically active radiation $250 \mu \mathrm{mol} \mathrm{m} \mathrm{m}^{-2} \mathrm{~s}^{-1}$. Cold acclimation was achieved by changing the day and night temperature to $2{ }^{\circ} \mathrm{C}$ (initially starting from $3 \mathrm{~h}$ into the night period, decreasing from $15{ }^{\circ} \mathrm{C}$ to $2{ }^{\circ} \mathrm{C}$ over $1 \mathrm{~h}$ ) for either 2 or 14 days prior to sub-zero conditions. Plants that were not cold acclimated remained at $20 / 15^{\circ} \mathrm{C}$. For sub-zero experiments, seedlings (approximately 2 weeks old) were transferred to a growth room capable of reproducibly ramping and holding sub-zero temperatures prior to the acclimation period (Conviron BDW-40 Controlled Environments Limited, Canada). Sub-zero experiments were carried out during the night cycle as this is when plants mainly experience such temperatures in their natural habitat. After $3 \mathrm{~h}$ into the night cycle the temperature was decreased to $-1{ }^{\circ} \mathrm{C}$ over $30 \mathrm{~min}$ and held at $-1{ }^{\circ} \mathrm{C}$ for a further $30 \mathrm{~min}$ in order for the growth room temperature to stabilise to the new sub-zero temperatures. The temperature was then decreased at a rate of $-2{ }^{\circ} \mathrm{Ch}^{-1}$. After the plants had been exposed to the desired temperature for approximately 10 min, plants were taken out of the growth cabinet and immediately placed into another growth cabinet at $2{ }^{\circ} \mathrm{C}$. After $24 \mathrm{~h}$ all plants were subjected to original control conditions $\left(20 / 15{ }^{\circ} \mathrm{C}\right)$ and percent survival of the plant was measured 14-16 days later to ensure non-ambiguity in whether plants were alive (new tissue forming) or not. Survival curves and $\mathrm{LT}_{50}$ values were fitted and calculated using the nonlinear regression - dynamic fitting 3 parameter sigmoidal equations in SigmaPlot v13 (Systat Software Inc., USA).

\section{Chlorophyll fluorescence}

Pre-acclimation and post-sub-zero measurements of chlorophyll fluorescence were taken using a chlorophyll fluorescence imager (Technologica LTD, Colchester). The maximum efficiency of photosystem II $\left(F_{v} / F_{m}\right)$ was measured by dark adapting plants for at least $30 \mathrm{~min}$ prior to the optimised conditions of a saturating blue light pulse at $3000 \mu \mathrm{mol} \mathrm{m}{ }^{-2} \mathrm{~s}^{-1}$ for $200 \mathrm{~ms}$ [39].

\section{Electrolyte leakage}

Larger mature leaves were used for the electrolyte leakage experiment in order to obtain reproducible results and were grown under a $10 / 14 \mathrm{~h}$ day/night cycle at $20^{\circ} \mathrm{C}$. Foliage electrolyte leakage was measured based on the methods by Rohde et al. [40]. Briefly, for each sub-zero temperature point of interest, four fully expanded leaves from four individual plants were placed (one per tube) into a $15 \mathrm{ml}$ plastic centrifuge tube containing $200 \mu \mathrm{l}$ of distilled water. Tubes were placed into a cooling water bath containing $50 \%$ anti-freeze (Ethanediol) set at $-1{ }^{\circ} \mathrm{C}$. After $30 \mathrm{~min}$ a few small ice chips were added to each tube to initiate nucleation. After a further $30 \mathrm{~min}$, the samples were cooled at a rate of $2{ }^{\circ} \mathrm{Ch}^{-1}$. Tubes were removed at $1{ }^{\circ} \mathrm{C}$ intervals and allowed to thaw on ice overnight. Six ml distilled water was added to each tube and shaken overnight at $4{ }^{\circ} \mathrm{C}$ in the dark. Once samples had reached room temperature the conductivity $(\mathrm{mV})$ of each sample solution was measured. The samples were then frozen at $-80{ }^{\circ} \mathrm{C}$ for $3 \mathrm{~h}$ to purge all the cell contents. Once thawed the samples were shaken overnight at $4{ }^{\circ} \mathrm{C}$ before final (total) conductivity measurements were made the following day. Percent electrolyte leakage was determined as the ratio of the conductivity measured before freezing at $-80{ }^{\circ} \mathrm{C}$ to that after.

\section{Statistical analyses}

XSurvival curves, lethal temperature $\left(\mathrm{LT}_{50}\right)$ and temperature at $50 \%$ electrolyte leakage $\left(\mathrm{TEL}_{50}\right)$ values were fitted and calculated using the nonlinear regression - dynamic fitting 3 parameter sigmoidal equations in SigmaPlot v13 (Systat Software Inc., USA). T-test were used to test for significant treatment effects within populations using SPSS v12.0.1 (Chicago, Illinois, USA).

\section{Abbreviations \\ $F_{v} / F_{m}$ : Maximum efficiency of photosystem $\|_{;} L T_{50}$ : Lethal temperature at 50\% survival; mV: Conductivity milliVolts; PSII: Photosystem II; RO: Reverse osmosis; TEL 50 : Temperature at 50\% electrolyte leakage; $\Phi_{\text {PSII }}$ : Operating efficiency of photosystem ॥}

\section{Acknowledgements}

We thank numerous field assistants for their efforts, Naomi Kingston of the Irish National Parks and Wildlife Service (Duchas), and Hywel Roberts and Barbara Jones of the Countryside Council for Wales, for assistance with research permits. 


\section{Funding}

This research was funded by the Natural Environment Research Council PostGenomics and Proteomics programme (NE/C507837/1). MPD was supported by a Leverhulme Trust Research award (RPG-2017-077) during the final writing and submission of the manuscript.

\section{Availability of data and materials}

Data generated or analysed during this study are either included in this published article or are available from the corresponding author on reasonable request.

\section{Authors' contributions}

MD, WK, IW and PQ developed the concept and interpreted the results. BP, $E A, M D, P V$ performed the laboratory, field work and data analysis. MD drafted the manuscript. All authors reviewed the manuscript and provided valuable feedback and have read and approved the final version of this manuscript.

\section{Ethics approval and consent to participate}

Seed collections were carried out with under permission from all land owners and complied with institutional, national, or international guidelines and legislation.

\section{Consent for publication}

Not applicable.

\section{Competing interests}

The authors declare that they have no competing interests.

\section{Publisher's Note}

Springer Nature remains neutral with regard to jurisdictional claims in published maps and institutional affiliations.

\section{Author details}

${ }^{1}$ Current address: Department of Plant Sciences, Downing Street, Cambridge CB2 3EA, UK. ${ }^{2}$ Animal and Plant Sciences, Western Bank, University of Sheffield, Sheffield, UK. ${ }^{3}$ Plant Ecology and Nature Conservation Group, Wageningen University, Wageningen, The Netherlands. ${ }^{4}$ Institute of Integrative and Comparative Biology, University of Leeds, Leeds, UK.

Received: 25 May 2018 Accepted: 31 October 2018

Published online: 12 November 2018

\section{References}

1. Le MQ, Engelsberger WR, Hincha DK. Natural genetic variation in acclimation capacity at sub-zero temperatures after cold acclimation at $4{ }^{\circ} \mathrm{C}$ in different Arabidopsis thaliana accessions. Cryobiology. 2008;57:104-12.

2. Zhen $Y$, Ungerer MC. Clinal variation in freezing tolerance among natural accessions of Arabidopsis thaliana. New Phytol. 2007;177:419-27.

3. Renaut J, Hoffmann L, Hausman J. Biochemical and physiological mechanisms related to cold acclimation and enhanced freezing tolerance in poplar plantlets. Physiol Plant. 2005;125:82-94

4. Wanner LA, Junttila O. Cold-induced freezing tolerance in Arabidopsis. Plant Physiol. 1999;120:391-9.

5. Guy C, Porat R, Hurry V. Plant cold and abiotic stress gets hot. Physiol Plant. 2006;126:1-4.

6. Zhu J, Dong $\mathrm{CH}$, Zhu JK. Interplay between cold-responsive gene regulation, metabolism and RNA processing during plant cold acclimation. Curr Opin Plant Biol. 2007:10:290-5.

7. Murray MB, Cape JN, Fowler D. Quantification of frost damage in plant tissues by rates of electrolyte leakage. New Phytol. 1989;113:307-11.

8. Nunes EMS, Smith GR. Electrolyte leakage assay capable of quantifying freezing resistance in rose clover. Crop Sci. 2003:43:1349-57.

9. Rohde P, Hincha DK, Heyer AG. Heterosis in the freezing tolerance of crosses between two Arabidopsis thaliana accessions (Columbia-0 and C24) that show differences in non-acclimated and acclimated freezing tolerance. Plant J. 2004;38:790-9.

10. Allen DJ, Ort DR. Impacts of chilling temperatures on photosynthesis in warm-climate plants. Trends Plant Sci. 2001;6:36-42.
11. Ducruet J, Peeva V, Havaux M. Chlorophyll thermofluorescence and thermoluminescence as complementary tools for the study of temperature stress in plants. Photosynth Res. 2007;93:159-71.

12. Finazzi G, Johnson GN, Dall'Osto L, Zito F, Bonente G, Bassi R, Wollman FA. Nonphotochemical quenching of chlorophyll fluorescence in Chlamydomonas reinhardtii. Biochemistry. 2006:45:1490-8.

13. Fracheboud Y, Haldimann P, Leipner J, Stamp P. Chlorophyll fluorescence as a selection tool for cold tolerance of photosynthesis in maize (Zea mays L.). Exp Bot. 1999:50:1533-40.

14. Krause GH. Photoinhibition induced by low temperatures. In: Baker NR, Bowyer JR, editors. Photoinhibition of photosynthesis from molecular mechanisms to the field. Oxford: Bios Scientific; 1994. p. 331-44.

15. Styring $S$, Jegerschöld C. Light induced reactions impairing electron transfer through photosystem II. In: Baker NR, Bowyer JR, editors. Photoinhibition of photosynthesis from molecular mechanisms to the field. Oxford: Bios Scientific; 1994. p. 51-69.

16. Demmig-Adams B. Carotinoids and photoprotection in plants - a role for the xanthophylls zeaxanthin. Biochim Biophys Acta. 1990;1020:1-24.

17. Quick WP. Stitt M. An examination of factors contributing to nonphotochemical quenching of chlorophyll fluorescence in barley leaves. Biochim Biophys Acta. 1989:977:277-96.

18. Lichtenhaler HK, Bushman C, Knapp M. How to correctly determine the different chlorophyll fluorescence parameters and the chlorophyll fluorescence decrease ratio RFd of leaves with the PAM fluorometer. Photosynthetica. 2005;43:379-93.

19. Aguilera C, Stirling CM, Long SP. Genotypic variation within Zea mays for susceptibility to and rate of recovery from chill-induced photoinhibition of photosynthesis. Physiol Plant. 1999;106:429-36.

20. Ehlert B, Hincha DK. Chlorophyll fluorescence imaging accuraTELy quantifies freezing damage and cold acclimation responses in Arabidopsis leaves. Plant Methods. 2008;27:4-12

21. Barbagallo RP, Oxborough K, Pallett KE, Baker NR. Rapid, noninvasive screening for perturbations of metabolism and plant growth using chlorophyll fluorescence imaging. Plant Physiol. 2003;132:485-93.

22. Hannah MA, Wiese D, Freund S, Fiehn O, Heyer AG, Hincha DK. Natural genetic variation of freezing tolerance in Arabidopsis. Plant Physiol. 2006; 142:98-112.

23. Alonso-Blanco C, Gomez-Mena C, Llorente F, Koornneef M, Salinas J, Martínez-Zapater JM. Genetic and molecular analyses of natural variation indicate CBF2 as a candidate gene for underlying a freezing tolerance quantitative trait locus in Arabidopsis. Plant Physiol. 2005;139:1304-12.

24. McKhann HI, Gery C, Bérard A, Lévêque S, Zuther E, Hincha DK, De Mita S, Brunel D, Téoulé E. Natural variation in CBF gene sequence, gene expression and freezing tolerance in the Versailles core collection of Arabidopsis thaliana. BMC Plant Biol. 2008:8:105.

25. Jonsell B, Kustås K, Nordal I. Genetic variation in Arabis petraea, a disjunct species in northern Europe. Ecography. 1995:18:321-32.

26. Gaudeul M, Stenøien HK, Ågren J. Landscape structure, clonal propagation, and genetic diversity in Scandinavian populations of Arabidopsis lyrato (Brassicaceae). Am J Bot. 2007;94:1146-55

27. Davey MP, Burrell MM, Woodward Fl, Quick WP. Population specific metabolic phenotypes of Arabidopsis lyrata ssp. petraea. New Phytol. 2008; 177:380-8.

28. Davey MP, Woodward FI, Quick WP. Intraspecfic variation in coldtemperature metabolic phenotypes of Arabidopsis lyrata ssp. petraea. Metabolomics. 2009;5:138-49.

29. Vergeer $P$, Kunin WE. Life history variation in Arabidopsis lyrata across its range: effects of climate, population size and herbivory. Oikos. 2011;120: 979-90.

30. Körner C. Alpine plant life: functional plant ecology of High Mountain ecosystems. 2nd ed. Berlin Heidelberg: Springer-Verlag; 2003.

31. Clauss MJ, Mitchell-Olds T. Population genetic structure of Arabidopsis lyrata in Europe. Molec Ecol. 2006;15:2753-66.

32. Inouye DW. The ecological and evolutionary significance of frost in the context of climate change. Ecol Lett. 2000;3:457-63.

33. Haldimann $P$, Fracheboud $Y$, Stamp P. Carotinoid composition in Zea mays developed at sub-optimal temperature and different light intensities. Physiol Plant. 1995:95:409-14

34. Haldimann P, Fracheboud Y, Stamp P. Photosynthetic performance and resistance to photoinhibition of Zea mays grown at sub-optimal temperatures. Plant Cell Environ. 1996;19:85-92. 
35. Atkin OK, Atkinsonw L, Fisher RA, Campbell CD, Zaragoza-CasTELIs J, Pitchford JW, Woodward Fl, Hurry V. Using temperature-dependent changes in leaf scaling relationships to quantitatively account for thermal acclimation of respiration in a coupled global climate-vegetation model. Glob Chang Biol. 2008;14:2709-26.

36. Strand Å, Hurry V, Gustafsson P, Gardeström P. Development of Arabidopsis thaliana leaves at low temperatures releases the suppression of photosynthesis and photosynthetic gene expression despite the accumulation of soluble carbohydrates. Plant J. 1997;12:605-14.

37. Davey MP, Susanti N, Wargent J, Findlay J, Quick WP, Paul N, Jenkins G. The UV-B photoreceptor UVR8 promotes photosynthetic efficiency in Arabidopsis exposed to high levels of UV-B. Photosyn Res. 2012;114:121-31.

38. Kunin WE, Vergeer P, Kenta T, Davey MP, Burke T, Woodward Fl, Quick P, Manerelli ME, Watson-Haigh NS, Butlin R. Variation at range margins across multiple spatial scales: environmental temperature, population genetics and metabolomic phenotype. Proc Roy Soc B. 2009;276:1495-506.

39. Maxwell K, Johnson GN. Chlorophyll fluorescence - a practical guide. J Exp Bot. 2000;51:659-68.

40. Ristic Z, Ashworth EN. Changes in leaf ultrastructure and carbohydrates in Arabidopsis thaliana L. (Heyn) cv. Columbia during rapid cold acclimation. Protoplasma. 1993;172:111-23.

Ready to submit your research? Choose BMC and benefit from:

- fast, convenient online submission

- thorough peer review by experienced researchers in your field

- rapid publication on acceptance

- support for research data, including large and complex data types

- gold Open Access which fosters wider collaboration and increased citations

- maximum visibility for your research: over $100 \mathrm{M}$ website views per year

At $\mathrm{BMC}$, research is always in progress.

Learn more biomedcentral.com/submissions 